\title{
A Step Forward in Disclosing the Secret of Stradivari's Varnish by NMR Spectroscopy
}

\author{
Alberto Spinella (D), ${ }^{1}$ Marco Malagodi, ${ }^{2,3}$ Maria Luisa Saladino, ${ }^{4}$ Maduka L. Weththimuni, ${ }^{5}$ \\ Eugenio Caponetti, ${ }^{1,4}$ Maurizio Licchelli ${ }^{3,5}$ \\ ${ }^{1}$ Centro Grandi Apparecchiature (CGA)-ATeN Center, University of Palermo, via F. Marini 14, 90128, Palermo, Italy \\ ${ }^{2}$ Department of Musicology and Cultural Heritage, University of Pavia, Corso Garibaldi 178, 26100, Cremona, Italy \\ ${ }^{3}$ CISRiC -Arvedi Laboratory of Non-Invasive Diagnostics, University of Pavia, Via Bell'Aspa 3, 26100, Cremona, Italy \\ ${ }^{4}$ Department of Biological, Chemical, and Pharmaceutical Sciences and Technologies (STEBICEF), University of Palermo, Viale \\ delle Scienze ed. 17, 90128, Palermo, Italy \\ ${ }^{5}$ Department of Chemistry, University of Pavia, via Taramelli 12, 27100, Pavia, Italy \\ Correspondence to: A. Spinella (E-mail: alberto.spinella@unipa.it)
}

Received 11 July 2017; accepted 29 August 2017; published online 25 September 2017

DOI: $10.1002 /$ pola.28782

ABSTRACT: It is commonly thought that the varnishes used by the great violin-maker Antonio Stradivari may have a role in determining not only the esthetical features but also the acoustic properties of his instruments, and the idea of a "lost secret" is still widespread among musicians and violin-makers. Previous scientific researches on varnish samples of Stradivari's instruments revealed that they were generally made by a mix of linseed oil with and colophony or metal rosinates in different ratios ranging between 75/25 (oil/resin) and 60/40 (oil/rosinate). However, it is still not clear whether the mixture composition can be related to any structural and/or functional feature of the resulting varnish. To investigate this aspect, we prepared varnishes with different linseed oil/colophony $(\mathrm{w} / \mathrm{w})$ ratios and applied
NMR techniques to achieve information about their chemicalphysical characteristics. Here, we show that the two components strongly interact in the solid state and that only the varnish prepared from 75/25 (w/w) linseed oil/colophony mixture displays unique properties in terms of dynamic homogeneity unlike coatings with other compositions. Our results suggest that the so-called "secret" of Stradivari's finish could not be related to unknown ingredient(s) but to a specific oil/resin composition that provides the best performance. (c) 2017 Wiley Periodicals, Inc. J. Polym. Sci., Part A: Polym. Chem. 2017, 55, 3949-3954

KEYWORDS: Antonio Stradivari; blends; molecular dynamics; NMR; violin varnish
INTRODUCTION Coatings made of siccative oils (e.g., linseed oil) and diterpenic resins, especially Pinaceae ones (e.g., colophony) were commonly used between the 15th and 18th century $^{1}$ to protect precious wooden artworks and to enhance their appearance and esthetical value. ${ }^{2}$ Siccative oils mainly contain triglycerides of saturated and unsaturated fatty acids, which "dry" when exposed to air due to a radical polymerization involving polyunsaturated acyl chains. They were well known since the 16th century as binders for varnishes, owing to their ability to provide very glossy and transparent coatings. However, the addition of some vegetal resins to oil became a rather common practice to obtain more elastic coating films. ${ }^{3}$ In particular, such varnishes were applied on stringed musical instruments created by famous violin-makers such as Antonio Stradivari. Many assumptions have been made about the "legendary" nature of Stradivari's finish, which could positively affect not only the appearance of the instruments but even their acoustic properties. Despite several scientific investigations, a clear understanding of Stradivari's finishing technique has been not gained yet and the idea of a "lost secret" is still widespread among musicians, violin-makers, and common people. ${ }^{4}$

Studies performed over the past decades have confirmed that linseed oil and colophony (or equivalent compounds) were the main components of varnishes in several instruments made by Stradivari ${ }^{5,6}$ Different composition ratios were suggested for investigated varnishes on the basis of the experimental results, mainly ranging between 75/25 (oil/ resin) ${ }^{3}$ and $60 / 40$ (oil/rosinate). ${ }^{7}$

In recent years historical varnishes were "rediscovered" by violin makers, although contemporary coatings are usually prepared from oil/colophony mixtures with increased content of resin (up to a ratio of 1:1) with the aim of improving varnish elasticity. Blending of colophony with linseed oil

Additional Supporting Information may be found in the online version of this article. 


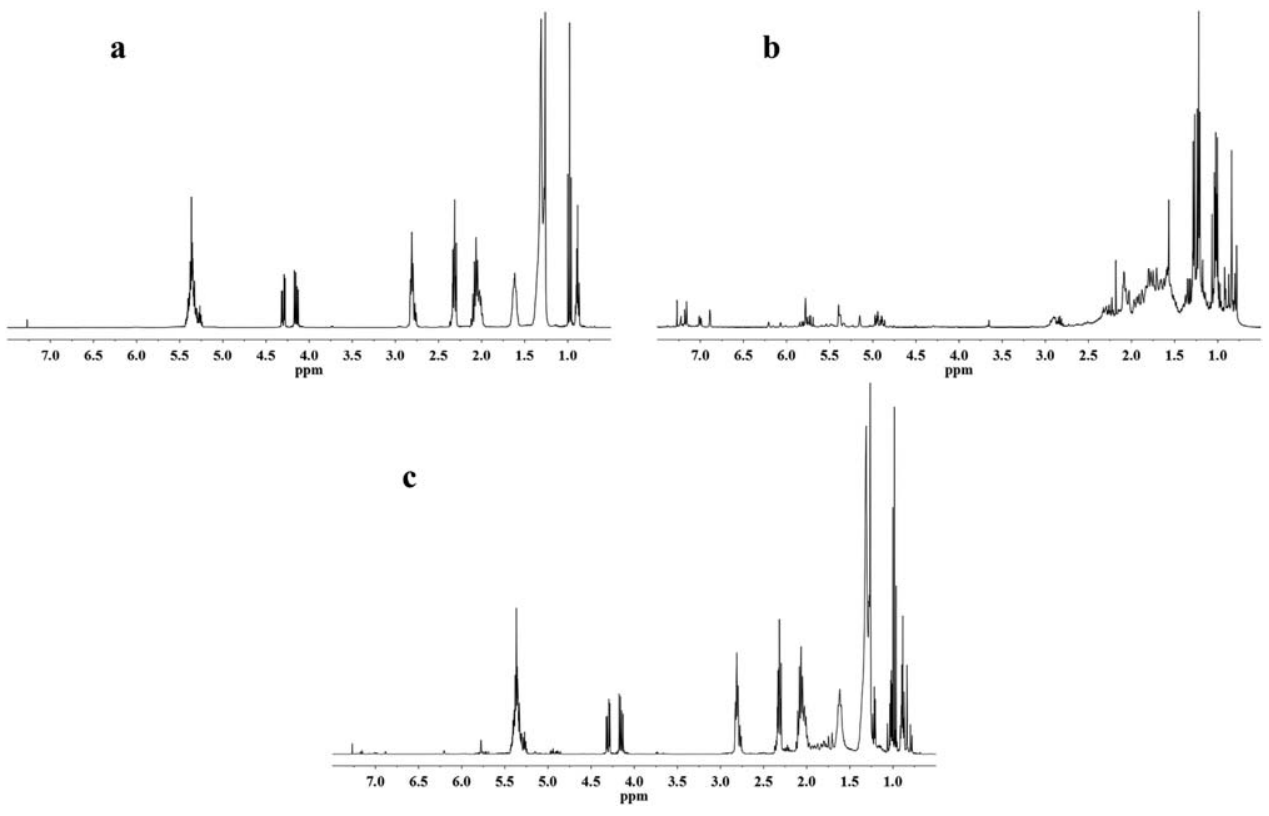

FIGURE $1{ }^{1} \mathrm{H}-\mathrm{NMR}$ in $\mathrm{CDCl}_{3}$ of pure linseed oil (a), pure colophony (b), and of the 75/25 mixture (c) ( $\mathrm{CDCl}_{3}, 300 \mathrm{~K}$ and radio frequency field of $20.4 \mathrm{kHz}$ ).

requires a heat treatment at a temperature higher than $200^{\circ} \mathrm{C}$. The effects induced by heating on the single components are well known. ${ }^{8-11}$ The authors found that the corresponding chemical modifications occurring to diterpenic acids of colophony and to (poly)unsaturated triglycerides in linseed oil are mainly due to oxidation and isomerization processes. $^{12}$ The study of the two-component mixture and of the reactions that can occur between oil and colophony is very complex, and thus only a few researchers investigated the mechanisms involved in the interactions between the components at a molecular level. In particular, it has been hypothesized not only that the compounds inside oil and resin can react by forming hybrid species but also that their reactivity depends on the relative composition of the mixture. ${ }^{13}$ Moreover, the mixture's relative composition appears to affect the varnishes conservation state. ${ }^{14}$

Nevertheless, it is still not clear whether linseed oil/colophony ratio can be related to peculiar structural and/or functional features of the resulting varnish layer.

Motivated by this open question, we prepared a set of varnishes with different oil/colophony ratios (35/65, 50/50, $65 / 35,75 / 25$, and $90 / 10$ ) according to an ancient recipe. ${ }^{15}$ Subsequently, we analyzed the oil/colophony mixtures by both liquid and solid state NMR techniques with an approach that is often adopted in material science for the characterization of polymeric blends. Finally, pure components underwent similar treatments as their mixtures and were analogously analyzed as references.

\section{EXPERIMENTAL}

\section{Varnishes Preparation}

Linseed oil (n73054 Kremer) was supplied by KremerPigmente and colophony was purchased from Cremona- tools. Both materials were used without any further purification.

Varnishes were prepared following an ancient recipe. According to the reported procedure, linseed oil was heated up to $270{ }^{\circ} \mathrm{C}$ and it was maintained at this temperature for 3 hours. After that, the cooked linseed oil was cooled to $150{ }^{\circ} \mathrm{C}$ and milled colophony was added according to the envisaged oil/resin weight ratio. The resulting mixture was heated again at $250^{\circ} \mathrm{C}$ for other $30 \mathrm{~min}$. Five linseed oil/colophony mixtures with different composition (90/10, 75/25, 65/35, $50 / 50$, and 35/65 oil/colophony) were prepared and stored under nitrogen atmosphere, at room temperature in the dark until they were analyzed.

The curing process was performed under UV light (2 Black Light Blue 18W lamps, Narva, Germany) for 2 days to accelerate the siccative process.

\section{Liquid State NMR}

All samples ( $\sim 15 \mathrm{mg}$ ) were completely solubilized in deuterated chloroform $\left(\mathrm{CDCl}_{3}\right)$. The spectra were recorded at $300 \mathrm{~K}$ using a Bruker Avance II 400 spectrometer operating at 400.15 and $100.63 \mathrm{MHz}$ for ${ }^{1} \mathrm{H}$ and ${ }^{13} \mathrm{C}$, respectively. The instrument was equipped with an inverse broadband probe.

For the acquisition of ${ }^{1} \mathrm{H}$ spectra, a $12.15-\mu$ s pulse, a delay time of $3 \mathrm{~s}$, and 4 scans were used.

The diffusion coefficients were determined at $300 \mathrm{~K}$ by diffusion ordered spectroscopy (DOSY) using a 2D sequence of stimulated eco using bipolar gradients.

The 2D nuclear overhauser spectroscopy (NOESY) spectrum was acquired at $300 \mathrm{~K}$ using a mixing time of $0.7 \mathrm{~s}$, a delay 
in the second dimension of $8.9 \mu \mathrm{s}, 16$ scans, and 256 experiments at the second dimension.

\section{Solid State NMR}

The solid state spectra were acquired using the spectrometer described above but with a $2.5-\mathrm{mm}$ (H/F-X) cross polarization magic angle spinning (CPMAS) probe. All samples were placed in $2.5 \mathrm{~mm}$ zirconia rotors filled with Vespel caps.

${ }^{13} \mathrm{C}$ CPMAS NMR spectra were acquired with a MAS speed of $10 \mathrm{kHz}, 1024$ scans, a contact time of $1.5 \mathrm{~ms}$, a delay time of $3 \mathrm{~s}$, and an excitation pulse of $2.5 \mu$ s on the ${ }^{1} \mathrm{H}$ nucleus. The optimization of the Hartmann-Hahn condition was obtained using an adamantane standard sample. This compound was also used as the external chemical shift reference.

The spin-lattice relaxation times in the rotating frame $\left(T_{1 \rho} \mathrm{H}\right)$ were determined by the variable spin lock pulse sequence. Data were acquired using spin-lock pulses ranging from 0.1 to $7.5 \mathrm{~ms}$ with a spin lock $\mathrm{B}_{1}$ field of $57.6 \mathrm{kHz}$ and a contact time of $1.5 \mathrm{~ms}$. The signals at $38 \mathrm{ppm}$ of the colophony due to the $\mathrm{C}-1$ and $\mathrm{C}-14$ of the abietic acid and the signal at 30 ppm which is due to the methylene groups of the fatty acids were integrated and the obtained values were plotted versus the spin lock pulse duration. The experimental points were fitted by the Origin 8.0 software through an exponential decay function. The errors of the $T_{1 \rho} \mathrm{H}$ values were provided by the software after the fitting process.

\section{RESULTS AND DISCUSSION}

The main aim of this work was to understand whether a particular ratio can provide special features to the resulting coating and to put into evidence interactions between linseed oil and colophony before and after varnish drying. Pure linseed oil and colophony as well as their mixtures were at first examined in deuterated chloroform solution.

Liquid state ${ }^{1} \mathrm{H}-\mathrm{NMR}$ spectra of linseed oil, colophony, and of the 75/25 mixture before the curing process are reported in Figure $1(\mathrm{a}-\mathrm{c})$ (see figure $\mathrm{S} 1$ in the supporting information for $1 \mathrm{H}$ spectra of all mixtures). The spectra show several signals due to their rather complex nature and the consequent high number of different protons in their molecular structures. However, most of the peaks can be unambiguously assigned.

The ${ }^{1} \mathrm{H}$-NMR spectrum of linseed oil shows signals between 5.1 and $5.4 \mathrm{ppm}$ due to the $\mathrm{CH}$ of the triglyceride molecules and of unsaturated vinyl protons of fatty acids. The signals between 4.1 and 4.4 belong to the $\mathrm{CH}_{2}$ of triglycerides, 1,2diglycerides, and 1,3-diglycerides. The signals at $2.8 \mathrm{ppm}$ are due to the $\mathrm{CH}_{2}$ between double bonds. The multiplet at 2.3 ppm is due to $\mathrm{CH}_{2}$ ester bonded to carbonyl groups while the one at $2.0 \mathrm{ppm}$ is referred to the $\mathrm{CH}_{2}$ bonded to one double bond. The signal due to the $\mathrm{CH}_{2}$ bonded to methylene ester groups is present at $1.6 \mathrm{ppm}$ and the intense resonance at $1.3 \mathrm{ppm}$ was assigned to the aliphatic methylene chains. Finally, the two triplets at 0.9 and $0.8 \mathrm{ppm}$ are due

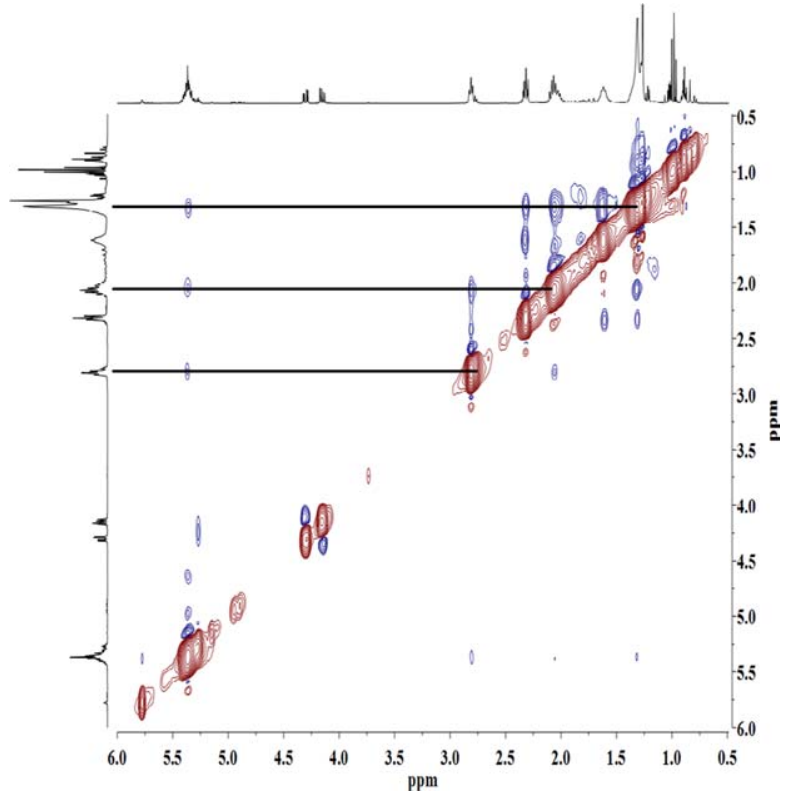

FIGURE 2 2D-NOESY spectrum $\left(\mathrm{CDCl}_{3}, 300 \mathrm{~K}\right.$, and radio frequency field of $20.5 \mathrm{kHz}$ ) of linseed oil/colophony 75/25 w/ w mixture. Lines indicate the intramolecular interaction patterns. [Color figure can be viewed at wileyonlinelibrary.com]

to terminal methyl groups of the linolenic acid and other fatty acids, respectively. ${ }^{16}$

${ }^{1} \mathrm{H}-\mathrm{NMR}$ spectrum of colophony can be divided in four zones. In the spectral region between 0.5 and $1.2 \mathrm{ppm}$, sharp signals due to methyl groups can be observed. The resonances between 1.2 and $2.0 \mathrm{ppm}$ belong to methylene groups. The signals in the spectral region between 4.7 and $6.0 \mathrm{ppm}$ are due to the endo and exocyclic double bonds of abietic acid. Finally, the signals between 6.8 and $7.3 \mathrm{ppm}$ are due to the aromatic protons of abietic acid. ${ }^{17}$

${ }^{1} \mathrm{H}$-NMR spectra of mixtures show overlapping signals due to each single components. Their relative intensities depend on the composition of each blend. As an example, the ${ }^{1} \mathrm{H}-\mathrm{NMR}$ spectrum of 75/25 mixture in $\mathrm{CDCl}_{3}$ is reported in Figure 2.

Diffusion coefficients $\left(D_{0}\right)$ for linseed oil and colophony in their mixtures determined by DOSY to gather information

TABLE 1 Diffusion Coefficients Determined by DOSY Experiments $\left(\mathrm{CDCl}_{3}, 300 \mathrm{~K}\right.$ and Radio Frequency Field of $\left.20.5 \mathrm{kHz}\right)$ for Linseed Oil and Colophony in Their Mixtures

\begin{tabular}{llc}
\hline & \multicolumn{2}{c}{$\begin{array}{c}\text { Diffusion Coefficients, } \\
D_{0}\left(\mathrm{~m}^{2} / \mathrm{s} \cdot 10^{-10}\right)\end{array}$} \\
\cline { 2 - 3 } & \multicolumn{1}{c}{ Linseed Oil } & Colophony \\
$75 / 25$ & $7.3 \pm 0.1$ & $8.6 \pm 0.2$ \\
$65 / 35$ & $5.6 \pm 0.2$ & $6.6 \pm 0.2$ \\
$50 / 50$ & $8.3 \pm 0.2$ & $8.9 \pm 0.2$ \\
$35 / 65$ & $5.5 \pm 0.2$ & $6.4 \pm 0.2$
\end{tabular}




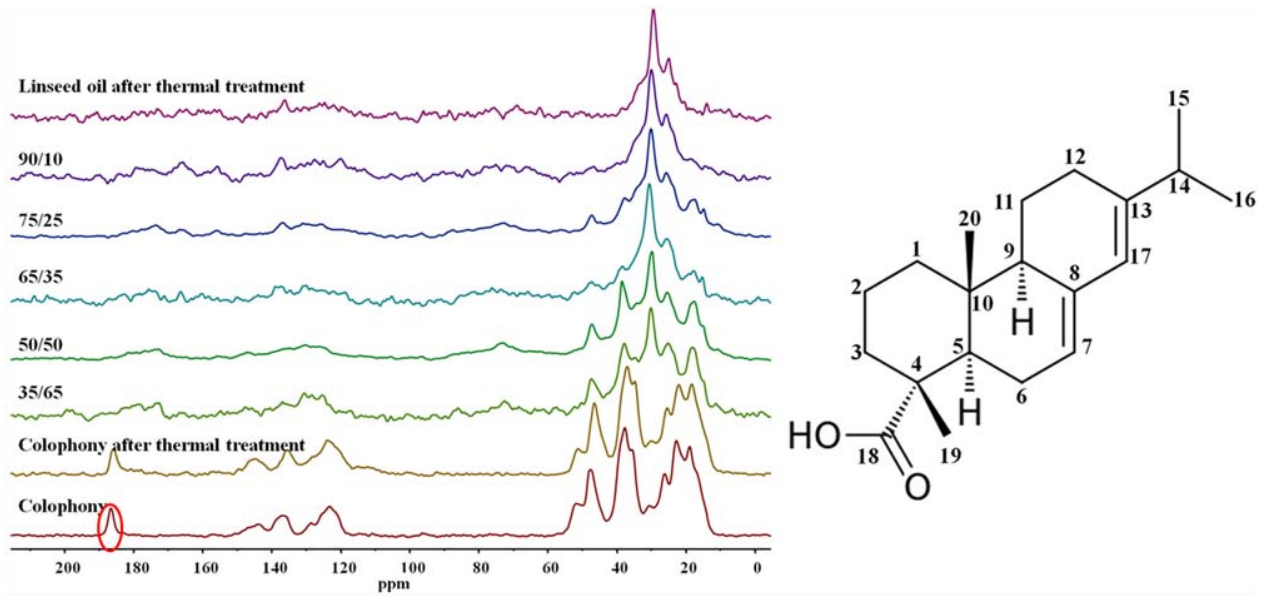

FIGURE $3{ }^{13} \mathrm{C}$ CPMAS NMR spectra of pure colophony before and after curing, linseed oil after curing, and all varnishes. On the right side of the figure, the structure of the abietic acid is reported. [Color figure can be viewed at wileyonlinelibrary.com]

about their motional behavior in the different blends before the curing process are reported in Table 1.

$D_{0}$ values obtained for linseed oil and colophony after the heat treatment required for the mixtures preparation are clearly distinct. This suggests that two components have different motional behavior before varnish drying process probably due to scarce interactions at molecular level.

This finding was confirmed by dipolar correlation experiments (2D-NOESY) performed on all the investigated mixtures before the curing process to have information about the spin-spin couplings through space. The NOESY spectrum of the 75/25 blend is reported in Figure 2, as an example (see figure S2 in the supporting information for NOESY spectra of all mixtures).

The cross peaks in the 2D NOESY spectrum are due to intramolecular dipolar correlations and are related only to fatty acids of the linseed oil. No cross peaks related to signals of linseed oil and colophony can be observed in any of the analyzed mixtures, thereby indicating the absence of strong intermolecular interactions between linseed oil and colophony. These data support the hypothesis that the components of the oil and those of the resin fractions are poorly linked together before the drying process, though the occurrence of reactions and the formation of "hybrid species" just upon heat treatment could be expected on the basis of previous studies. ${ }^{13}$

Varnishes obtained after the curing of the different oilcolophony mixtures were analyzed by high resolution solid state NMR experiments. Cured linseed oil was also examined for comparison while spectra of colophony were taken on the native resin and after the thermal and the UV-curing treatments. Although in recent years, solid state NMR has been used to examine wood samples taken from some Stradivari's instruments, the application of this technique to the characterization of varnishes is not very widespread. ${ }^{18,19}{ }^{13} \mathrm{C}$ CPMAS NMR spectra of pure components and their mixtures are reported in Figure 3 together with the abietic acid structure. The assignments of the signals in the carbon spectra were carried out taking into account the corresponding spectra in solution

Spectrum of colophony is typical of diterpene compounds which are the constituents of the resin. The abietic acid structure was taken as reference for the chemical shift assignment reported in Table 2 being the most abundant.

Spectra of coatings obtained from the different mixtures show the signals due to cured oil and resin compounds (Fig. 3). It should be noted that the signal resonating at $187 \mathrm{ppm}$ (indicated by the red circle in Fig. 3) due to the carboxyl group of abietic acid is not present in the spectra of varnishes.

On a first attempt, we attributed the disappearing of the aforementioned signal to a possible decarboxylation occurring during the heating $\left(>200^{\circ} \mathrm{C}\right)$ and/or the UV-curing process, according to literature data. ${ }^{10,11}$ However, a closer evaluation of our data suggested another possible explanation. In fact, the spectrum of colophony that underwent the same treatment as the mixtures, does not display substantial changes if compared with the spectrum of the native resin. This indicates that acidic

TABLE $2{ }^{13} \mathrm{C}$ CPMAS NMR Chemical Shift Assignments

\begin{tabular}{ll}
\hline $\begin{array}{l}\text { Chemical Shift } \\
15-35 \mathrm{ppm}\end{array}$ & $\begin{array}{r}{ }^{13} \mathrm{C} \text { Assignment } \\
\text { Methyl groups }(\mathrm{C}-15,16,19,20) \text { and } \\
\text { methylene }(\mathrm{C}-1,2,3,6,11,12) \\
\text { groups (linseed oil and abietic acid) }\end{array}$ \\
$30 \mathrm{ppm}$ & $\begin{array}{c}\text { Methylene groups of the fatty acids chains } \\
\text { (linseed oil) }\end{array}$ \\
$38 \mathrm{ppm}$ & Overlapping C-1 and C-14 bands (abietic acid) \\
$48 \mathrm{ppm}$ & C-4 bonded to carboxyl group (abietic acid) \\
$51 \mathrm{ppm}$ & C-5 and C-9 (abietic acid) \\
$123 \mathrm{ppm}$ & C-7 and C-17 (abietic acid) \\
$137 \mathrm{ppm}$ & C-8 (abietic acid) \\
$144 \mathrm{ppm}$ & C-13 (abietic acid) \\
$187 \mathrm{ppm}$ & C-18 carboxyl group (abietic acid)
\end{tabular}




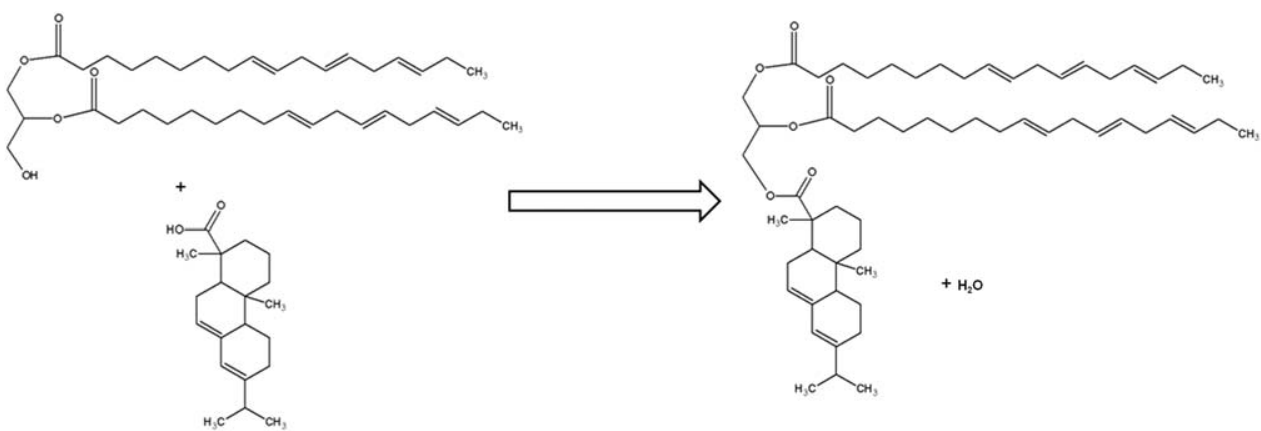

FIGURE 4 A scheme of the esterification reaction between a diglyceride compound and the abietic acid.

components of colophony do not experience $\mathrm{CO}_{2}$ loss or other reactions involving - $\mathrm{COOH}$ group even after thermal treatment and curing process. However, a signal at $173 \mathrm{ppm}$ can be observed in all the coatings spectra, which can be due to the resonance of an ester carbonyl group. Therefore, we hypothesize that the carboxyl group of the abietic acid (and so also the related compounds) is involved in an esterification process, with a consequent high-field shift of the corresponding peak in the ${ }^{13} \mathrm{C}$-NMR spectrum.

This observation confirms the formation of hybrid species, obtained by reaction between diterpenic carboxylic acids of resin and triglyceride components of the oil, which were detected by a recent microchemical chromatographic study. ${ }^{13}$ The same "mixed" esters could be obtained from diglyceride compounds (derived from partial hydrolysis of triglyceride analogues) and the same diterpenic acids. ${ }^{14}$ An example of the esterification process between a diglyceride compound and the abietic acid is reported in Figure 4.

However, the resin components are covalently bound to the crosslinked structure derived from the curing of the linseed oil.

The proton spin-lattice relaxation times in the rotating frame $\left(T_{1 \rho} \mathrm{H}\right)$ were obtained to have information on the miscibility of linseed oil and colophony in the cured mixtures at molecular level.

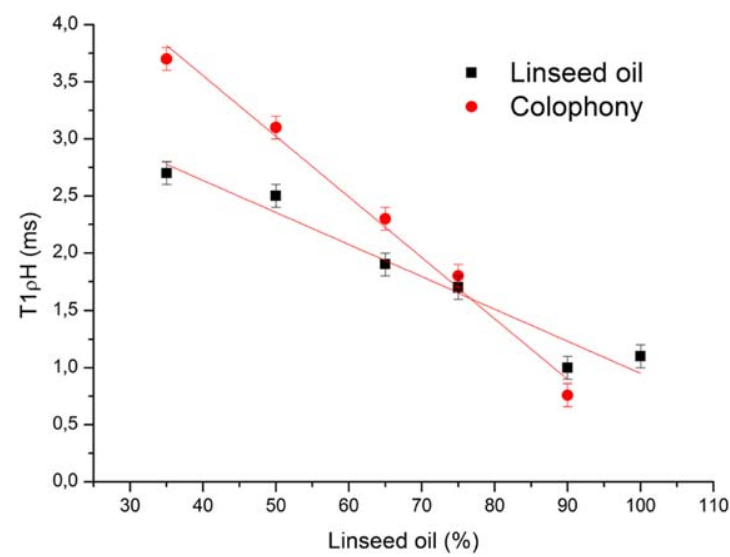

FIGURE $5 T_{1 \rho} \mathrm{H}$ values of linseed oil and colophony in coatings derived from their mixtures as function of the linseed oil content. [Color figure can be viewed at wileyonlinelibrary.com]
$T_{1 \rho}$ values provide information on molecular motions that occur in the kilohertz region. Such motions are associated with polymer backbone rearrangements involving collective motions of monomer units. ${ }^{20}$

It is well known that $T_{1 \rho} \mathrm{H}$ relaxation times are dominated by the spin diffusion phenomenon that, in polymers, tends to average out $T_{1}$ 's of all protons to a unique value. Despite this, relaxation analysis of heterogeneous systems such as polymeric blends can furnish valuable information. ${ }^{21}$

In particular, identical $T_{1 \rho}$ values for the two components of a blend indicate that polymeric chains are strongly coupled and relax at the same rate because of the spin diffusion mechanism. A blend is then homogenous and the components intimately miscible in a scale of tens of angstroms when the $T_{1 \rho} \mathrm{H}$ values of the two components are equal within the experimental error. ${ }^{22}$

For the relaxometric analysis, the signal at $38 \mathrm{ppm}$ of the colophony due to the $\mathrm{C}-1$ and $\mathrm{C}-14$ of the abietic acid and the signal at $30 \mathrm{ppm}$ which is due to the methylene groups of the fatty acids were chosen.

The $T_{1 \rho} \mathrm{H}$ values of two components in the cured mixtures are reported in Figure 5 as function of the linseed oil content (see table S1 in the supporting information).

From the analysis of the relaxation times, it is worth noting that all samples show different $T_{1 \rho} \mathrm{H}$ values for linseed oil and colophony except for the 75/25 mixture, which can be considered a homogeneous material in a scale of tens of angstroms as $T_{1 \rho} \mathrm{H}$ values determined for the resin and oil components are equivalent within the experimental error. To deepen this aspect, a linear fit was performed on the two sets of $T_{1 \rho} \mathrm{H}$ values. It was surprising to find that the two lines match in a point corresponding to a varnish of theoretical composition of 76.5/23.5.

\section{CONCLUSIONS}

This study affords further important information about the oil/colophony varnishes used by the ancient violin-maker Antonio Stradivari.

Liquid state high resolution NMR experiments are allowed to show that no strong interactions at molecular level (e.g., 
covalent bonds) take place between the two components before varnish drying process. Solid state NMR analysis confirmed that the resin and oil components react together during the drying step through an esterification process that forms hybrid ester species. Moreover, it is demonstrated that the dynamical properties of the blend materials obtained by curing oil/colophony mixtures strongly depend on their composition. It should be noted that mixture composition that provides the most homogeneous coating $(75 / 25 \mathrm{w} / \mathrm{w})$ roughly corresponds to a $1: 1$ stoichiometric ratio, if abietic acid and tri-linolenic glyceride are taken as representative compounds for colophony and linseed oil, respectively. These considerations suggest that the quality of the Cremonese finishing could be strongly related to the composition ratio of starting oil/resin mixtures: the choice of a "correct stoichiometric" ratio of the two main components, which allows optimizing their reaction and the consequent coating homogeneity, could represent a new way of looking at the so called "secret" of the Stradivari's varnish.

\section{ACKNOWLEDGMENTS}

This work is part of the project "Development and Application of Innovative Materials and processes for the diagnosis and restoration of Cultural Heritage-DELIAS"-PON03PE 002142 (Programma Operativo Nazionale Ricerca e Competitività 2007-2013). The authors thank Prof. Claudio Canevari, Civica Scuola di Liuteria, Milan, for the assistance and advices in preparation of varnishes, Dr. Giusj Fichera for her assistance in preliminary analysis of varnishes samples, and Prof. Pellegrino Conte of the Agricultural and Forestry Sciences Department at the University of Palermo for fruitful discussions.

\section{REFERENCES AND NOTES}

1 J. P. Echard, V. Malecki, In Making and Transforming Art: Technology and Interpretation; H. Dubois, J.-H. Townsend, J. Nadolny, S. Eyb-Green, S. Kroustallis, S. Neven, Eds.; Archetype: London, 2014; pp 131-132.

2 C. Daher, C. Paris, A. S. Le Hô, L. Bellot-Gurlet, J. P. Echard, J. Raman Spectrosc. 2010, 41, 1494.

3 B. Brandmair, S.-P. Greiner, In Stradivari Varnish: Scientific Analysis of His Finishing Technique on Selected Instruments;
B. Brandmair, S. P. Greiner, Eds.; Helmolz Publ.: London and Munich, 2010; p 11.

4 S. F. Sacconi, In I segreti di Stradivari; Libreria del convegno, Eds; Cremona, 1972; p 1-261.

5 J. P. Echard, C. Benoit, J. Peris-Vicente, V. Malecki, J. V. Gimeno-Adelantado, S. Vaiedelich, Anal. Chim. Acta. 2007, 584, 172.

6 J. P. Echard, L. Bertrand, A. Von Bohlen, A. S. L. Hô, C. Paris, L. Bellot-Gurlet, B. Soulier, A. Lattuati-Derieux, S. Thao, L. Robinet, B. Lavédrine, S. Vaiedelich, Angew. Chem. Int. 2010, 49, 197.

7 J. Michelman, Science 1950, 112, 337.

8 V. M. Loeblich, R. V. Lawrence, Ind. Eng. Chem. 1958, 50, 619.

9 I. Portugal, J. Vital, L. S. Lobo, Chem. Eng. Sci. 1996, 51, 2577.

10 G. F. Chen, Prog. Org. Coat. 1992, 20, 139.

11 K. J. Van den Berg, J. Boon, J. Mass Spectr. 2000, 35, 512.

12 J. D. J. Van den Berg, N. D. Vermist, L. Carlyle, M. Holcapek, J. Boon, J. Sep. Sci. 2004, 27, 181.

13 S. Tirat, I. Degano, J. P. Echard, A. Lattuati-Derieux, A. Lluveras-Tenorio, A. Marie, S. Serfaty, J. Y. Le Huerou, Microchem. J. 2016, 126, 200.

14 R. Rivenc, A. Phenix, B. Singer, N. Balcar, In De la Peinture de Chevalet à l'instrument de Musique: Vernis, Liants et Couleurs; J.-P. Echard, S. Vaiedelich, Eds.; Cité de la musique: Paris, 2008; pp 89-101.

15 P. Baraldi, Bolognese Manuscript 2861 (XV secolo), Biblioteca Universitaria di Bologna and F.Frezzato, C. Seccaroni, Segreti di arti diverse nel Regno di Napoli - Manuscript It. III 10 of the Biblioteca Marciana di Venezia, II Prato, Saonara (PD), march 2010.

16 A. Spyros, D. Anglos, Anal. Chem. 2004, 76, 4929.

17 A. B. Sifontes, B. Gutierrez, A. Mónaco, A. Yanez, Y. Díaz, F. J. Méndez, L. Llovera, E. Cañizales, J. L. Brito, Biotechnol. Rep. 2014, 4, 21.

18 H. C. Tai, G. C. Li, S. J. Huang, C. R. Jhu, J. H. Chung, Y. Bo, B. Y. Wang, C. S. Hsu, B. Brandmair, D. T. Chung, H. M. Chen, J. Chun Chung Chan, Proc. Natl. Acad. Sci. USA 2016, 114, 27.

19 J. Nagyvary, J. A. Di Verdi, N. L. Owen, H. D. Tolley, Nature 2006, 444, 565.

20 J. R. Garbow, J. Goetz, J. Asrar, Macromolecules 1998, 31, 3925.

21 S. Schantz, N. Ljungqvist, Macromolecules 1993, 26, 6517.

22 C. Lau, Y. Mi, Polymer 2002, 43, 823. 